\title{
Research of Thermal Energy Storage Technology in the Solar Thermodynamic Power
}

\author{
Yueru Zhang \\ North China Electric Power University, Beijing, China \\ Email: strawberryiangel@163.com
}

Received 27 June 2016; accepted 27 July 2016; published 30 July 2016

\begin{abstract}
Recently, although renewable energy has a great development, primary source is still thermal power generation, which uses fossil fuel as the energy source. Supply and demand of fossil fuel are essential for social and economy development. However, development pattern that excessively relies on the natural source is impossible to provide a sustainable development way for us. As a result, we should combine renewable energy with new energy technology as the aim of economy. It means that it is urgent to exploit new energy. Meanwhile, the ratio of energy waste cannot be ignored. How to decrease energy waste is also significant. Construction sector costs a lot of energy, which is mainly used for heating and refrigeration. In the new energy generation technology, thermal energy can be transformed to electricity with combination of BIPV and thermal energy storage technology. Photovoltaic generation has a great progress in the building construction. As a result, the thermal energy storage technology becomes the key link in the production chain. In this paper, feasibility of applying phase-change material (PCM) in the thermal energy storage will be analyzed. And analysis results are provided with a relative mathematical model.
\end{abstract}

\section{Keywords}

New Energy Power Generation, Sensible Heat Storage, Latent Heat Storage, Phase-Change Material

\section{Introduction}

New energy power generation is crucial technology of current developing electricity generation. Due to fossil fuel is finite and unfriendly to environment while applying it as energy source, it is unsatisfactory with strategy of sustainable development. New energy power generation has had a great progress in photovoltaic generation and wind power generation. Especially, Building Integrated Photovoltaics is most likely to have expected prospect. Meanwhile, we can realize the integration of heating system and generation system, which also realize thermal storage and transformation between thermal and electrical energy by inputting solar thermodynamic power system. To achieve it, thermal energy storage technology becomes an important problem to solve. This passage builds a simple model to analyze PCM's effect and efficient in buildings, which is the base of more 
complex analysis. Because of its distinctive thermal absorbing characteristic, PCM can effectively keep the temperature stable and make the material decreased.

\section{Background}

\subsection{Background Review}

Energy usage in world did not go in prospect sustainable direction. Petroleum price rise to the highest price leads to increasing attention to long-term demand and supply problem. In the last decade, emission of dioxide carbon had increased more than $20 \%$. It is predicted that emission would about treble than current emission. This worried situation can be changed with new energy power technology [1]. But there are potential factors in new technology development which can lead to diverse results. At least, we can assure that process of generation could achieve aim to decrease the cost by utilizing renewable energy, nuclear energy, carbon capture and sequestration technology.

Rapidly developing technology reminds us that it is imperative to make carbon emission in 2050 back to current level. If we want to achieve that, carbon emission should keep down until midterm of 21 century. In another word, in the future decades, electrical generation and transportation must pay more attention on the decarburization.

Look around the world, every country is continuously cut down the reliance on natural resources, expect in developed countries. For example, in England, energy consumption reaches to the lowest point with 193.4 million petrol's energy in 2014 since 1970, which is 6.6\% less than energy consumption in 2013 [2]. Ignoring the temperature factor, consuming energy reduce $2.6 \%$ than last year. It is demonstrated that from Figure 1 consuming energy is to be the least since 1984, although average temperature in 2014 rose to the summit of $10.9^{\circ} \mathrm{C}$.

Figure 2 shows fuel consumption. In 1970, solid energy consumption and petroleum consumption occupy about $90 \%$ in fundamental energy consumption, while electricity energy consumption is $3.5 \%$. It can be figured out that renewable energy ratio is gradually increasing. However, natural solid fuel ratio is declining more and more fast.

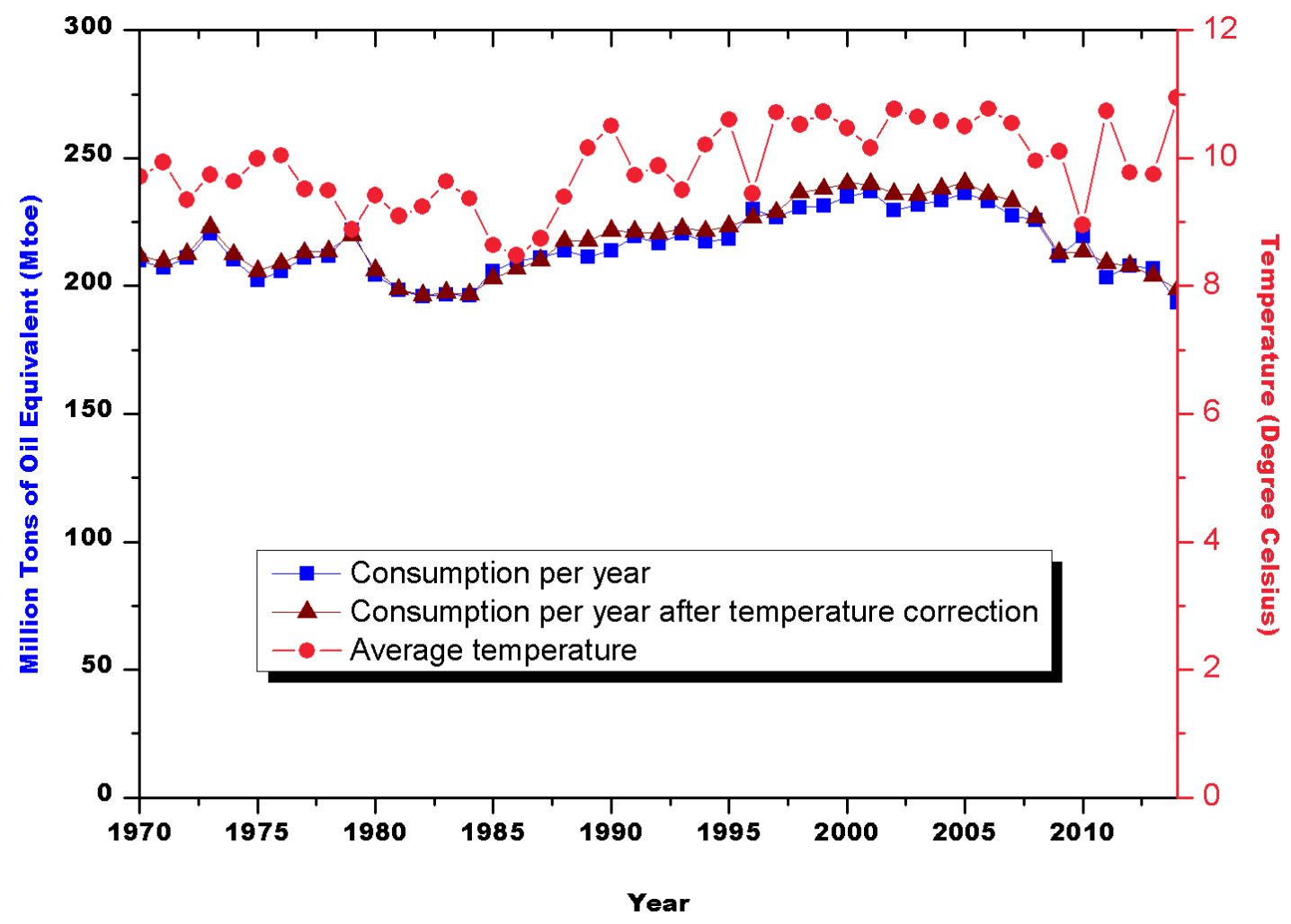

Figure 1. Fundamental energy consumption change from 1970 to 2010. 


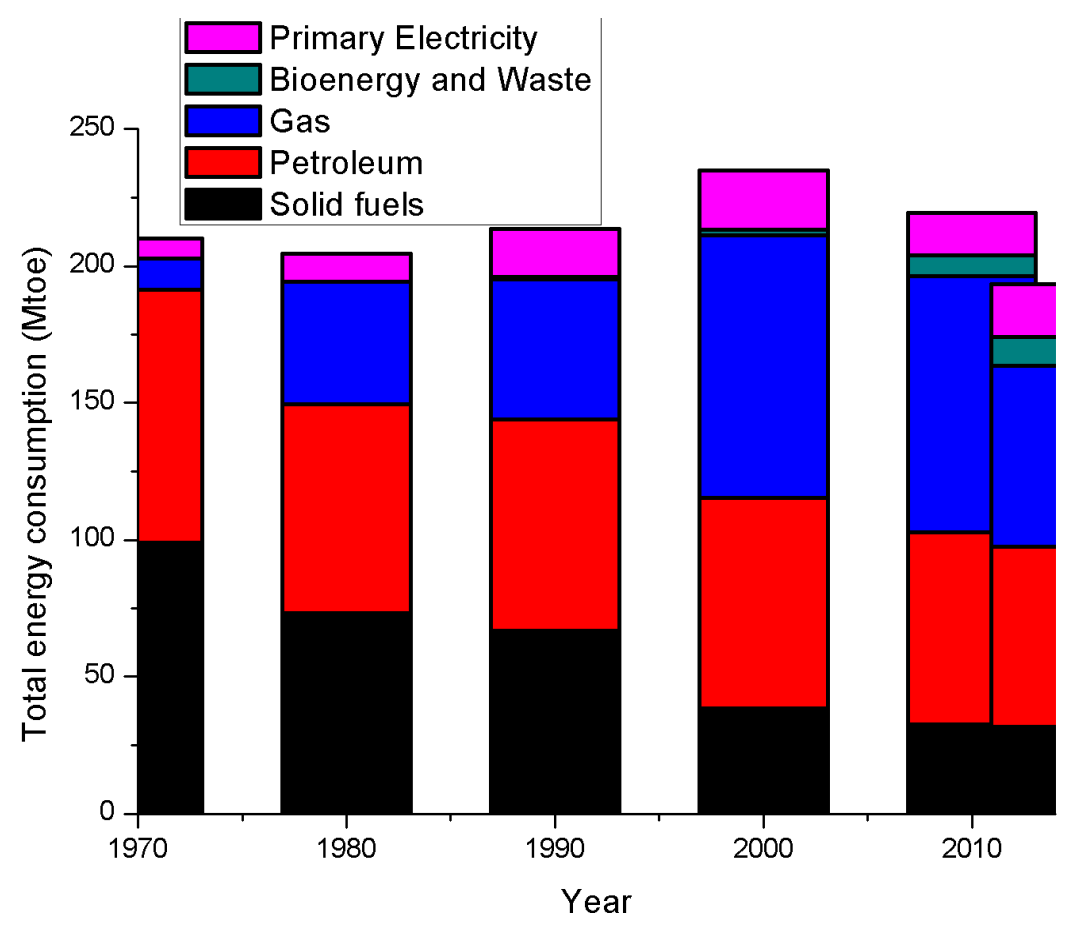

Figure 2. Fundamental energy consumption categories.

\subsection{Renewable Energy Classification}

Renewable Energy is the energy derived from nature and it is exhaustible because its renewability. Common renewable energy includes solar energy, wind energy, tidal energy, geothermal energy, etc. The world deeply realize that renewable energy is not only the key point of solving climate change, but also take significant effect in creating economy developing chance and improving the absence of energy. Except these, sustainable energy's influence on future sustainable development is not to be reckoned with. Among last several decades especially recent years, renewable energy make it to be true that technology advanced, global installation increased and cost sharply decrease because of relative policies issued. These benefits attract tremendous investment, and it takes a positive feedback on cost declining. As for developing countries with large population, economic pattern that over reliance on traditional fossil fuel reserves should not be the recommended one. Renewable energy applications in heating, cooling and transportation are less than in electrical area. To finish heating and generation integration, more effort should be taken on the new energy power heating.

Evidently, renewable energy has become dominated energy. Occupancy and application of fluctuant and stable renewable energy are both increasing, which promote energy structure to be diverse. Although new energy technology application expand swiftly, the target, in SE4ALL (Sustainable Energy for All), that double new energy ratio and global energy efficient growth rate and make sure everyone has energy before 2030 have not been accomplished.

\section{New Energy and Its Features}

New energy is energy which cannot be massively use because of technology, economy or quality factors. It includes part of renewable energy (solar energy 、 wind energy), geothermal energy and biomass energy. Sustainable energy system consist of new energy system and new energy utilizing technology, which includes using energy efficiently, utilizing resource comprehensively, replacing energy and conserving energy. New energy is not completely same as renewable energy. There is intersection between them.

\section{New Energy Power Generation in China}

China water electrical installed capacity is the largest in the world, followed by Brazil, Canada and Turkey. And 
China solar generation and biomass generation equipment's new installed capacity takes the leading position in the world while America and Germany have the world's leading biomass energy generating capacity. Application of new energy has continuous creation and more and more flexible、 efficient and reliable machines. To satisfy the demand of high-efficiency and low-cost, the power of electric generator is gradually going up, with some had risen up to $800 \mathrm{MW}$.

Installed capacity of generator driven by ocean energy, mainly by tidal energy, keep stable at about 530 MW. Almost all of new-added generators are on the trial project, which prevent tidal energy to have a great progress. If governments can build cooperation protocol and put tidal generation into practice, tidal generation can have an excepted future. China has a lengthy coastline with enormous development potential, so it can get more renewable energy from ocean.

By the time, china is the biggest construction market of the world. Energy waste of living is amazing. Adding new material in construction can significantly upgrade energy utilization rate and maximum limit use new energy, such as solar energy. Introducing new-type technology to modern life contributes to sustainable development. Thermal storage technology is easy to promote and popularize. And almost every country has preferential policy about it for the sake of guiding builder using thermal storage technology to cut down the cost of construction.

\section{Thermal Storage Technology}

Principle of phase-change storage is on the base of energy absorbance and emission when substance experiences solidification, melting, freezing, vaporization, condensation, sublimation or other phase-change progress to store thermal energy. There are two kinds of thermal storage energy, named by sensible heat storage and latent heat storage. Latent heat storage can be classified as low temperature and high temperature according to temperature value of PCM. Owning to direct photovoltaic conversion has a low conversion efficiency which is approximately $14 \%$ in normal and up to $20 \%-30 \%$ at most, it is not satisfied with demand of large power. Solar thermodynamic power system possesses plenty of advantages, such as light weight, high efficiency, small windward area and long life. As a result, solar thermodynamic power system is clearly better than photovoltaic generation. In recent years, America, Risa, Japan and Europe all devote much into research. The key technology of solar thermodynamic power system is phase-change material thermal storage technology. So research of PCM is essential.

\subsection{Sensible Heat Storage}

Sensible Heat Storage refers that thermal storage material's temperature changes with stored energy. The amount of energy transmission depends on the range of temperature change, so normally select material with large thermal energy storage capacity to store maximum energy. These materials must keep stable during thermal energy convert cycle time and compatible with stored container. What's more, it should have a reasonable price. Medium utilized as energy storage material is possible to exist as different form: liquid (like water and oil) or solid (like stone and metal).

\subsection{Latent Heat Storage}

Latent heat storage refers to stored progress using existence form change to achieve storing and emitting thermal energy. This technology can store energy with high density. Due to tiny temperature change could store large energy. There is no limit in material selection. Latent Heat Storage has such beneficial features that it is extensively used in construction. Under normal temperature of $20^{\circ} \mathrm{C}-30^{\circ} \mathrm{C}$, Latent heat storage store efficiency is 14 times than sensible heat storage.

\subsection{Standard of Choosing Latent Heat Storage Material}

When select right latent heat storage material, there are some criteria to think of:

- Thermal energy value (more than $130 \mathrm{KJ}$ in normal).

- Physical condition (high energy storage density is usually required).

- Kinetic energy (fast charge/discharge cycle).

- Reliability and compatibility (reaction with other material).

- Chemical considerations (fire proof, intoxicating). 
- Cheap and suitable.

There are many techniques for packaging PCM, depending on the application: macro capsules, polyethylene wafers, porous substrates, etc. Figure 3 shows temperature change in several days with PCM and without PCM. It is easy to conclude that appropriately utilize PCM can reduce the difference value between maximum and minimum temperature to keep temperature in a comfortable interval.

\subsection{Model and Analysis}

Figure 4 illustrates a schematic of a solar house capturing direct sunlight. And a model for the wall is built to analyze energy conduction progress and PCM's effect on temperature controlling [3] [4].

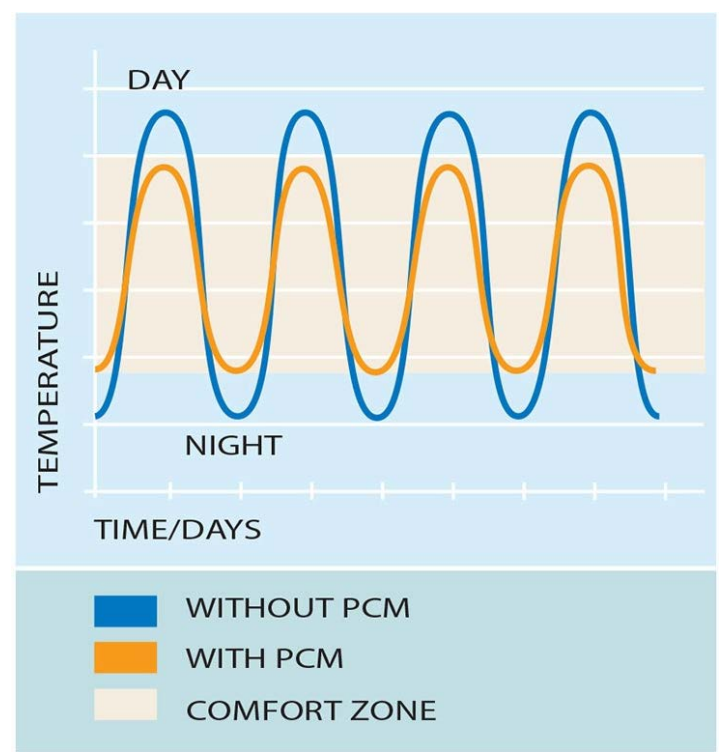

Figure 3. Influence of PCM on several days' temperature.

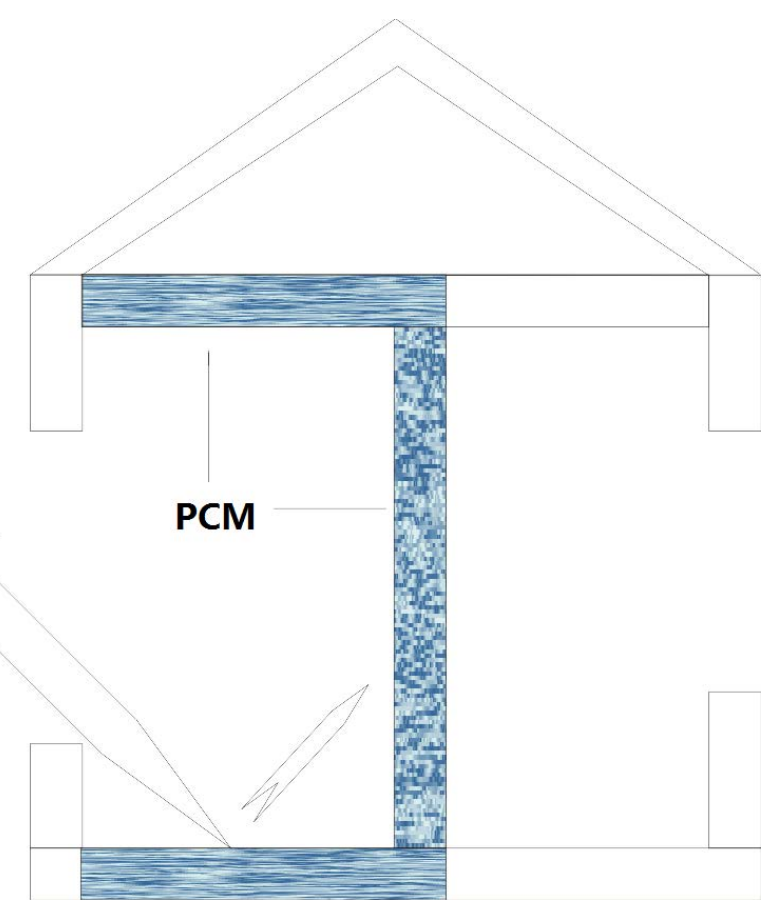

Figure 4. A house capturing direct sunlight. 


$$
\begin{gathered}
T_{m, o p t}\left({ }^{\circ} \mathrm{C}\right)=T_{r}+(Q / h) t_{\text {stor }} \\
D_{\text {opt }}\left({ }^{\circ} \mathrm{C}\right)=t_{n} h\left(T_{m, o p t}-T_{n}\right) /\left(t_{d}+t_{n}\right)
\end{gathered}
$$

And

$$
\begin{gathered}
T_{r}\left({ }^{\circ} \mathrm{C}\right)=\left(t_{d} T d+t_{n} T n\right) /\left(t_{d}+t_{n}\right) \\
t_{\text {stor }}=t_{d}+t_{n}
\end{gathered}
$$

where:

- $Q\left(\mathrm{~J} / \mathrm{m}^{2}\right)$ designs the heat absorbed per unit area of the room,

- $T_{r}\left({ }^{\circ} \mathrm{C}\right)$ is the room temperature,

- $T_{d}\left({ }^{\circ} \mathrm{C}\right)$ represents the room temperature during day,

- $T_{n}\left({ }^{\circ} \mathrm{C}\right)$ designs the room temperature during night,

- $t_{\text {stor }}(\mathrm{s})$ represents the thermal storage cycle time,

- $t_{d}(\mathrm{~s})$ is the charge time,

- $t_{n}(\mathrm{~s})$ is the discharge time.

The maximum useful amount of energy stored during the night by the unit area is:

$$
E_{\text {stor }}\left(\frac{J}{m^{2}}\right)=\rho \cdot \Delta h_{f} \cdot D_{o p t}
$$

where:

- $\rho\left(\mathrm{Kg} / \mathrm{m}^{3}\right)$ represents the PCM density,

- $\Delta h_{f}(\mathrm{~J} / \mathrm{Kg})$ designs the PCM fusion heat.

A wall, with a schematic presented in Figure 5, can be simply modeled by solving the equation of the conduction heat by the following assumptions: The wall and the PCM together are a single body with uniform physical and thermal properties (specific heat, density, conductivity and latent heat) [5] [6], The process of heat transfer through the wall to PCM is one-dimensional.

The equation of heat transfer, as per Fourier equation is [7]
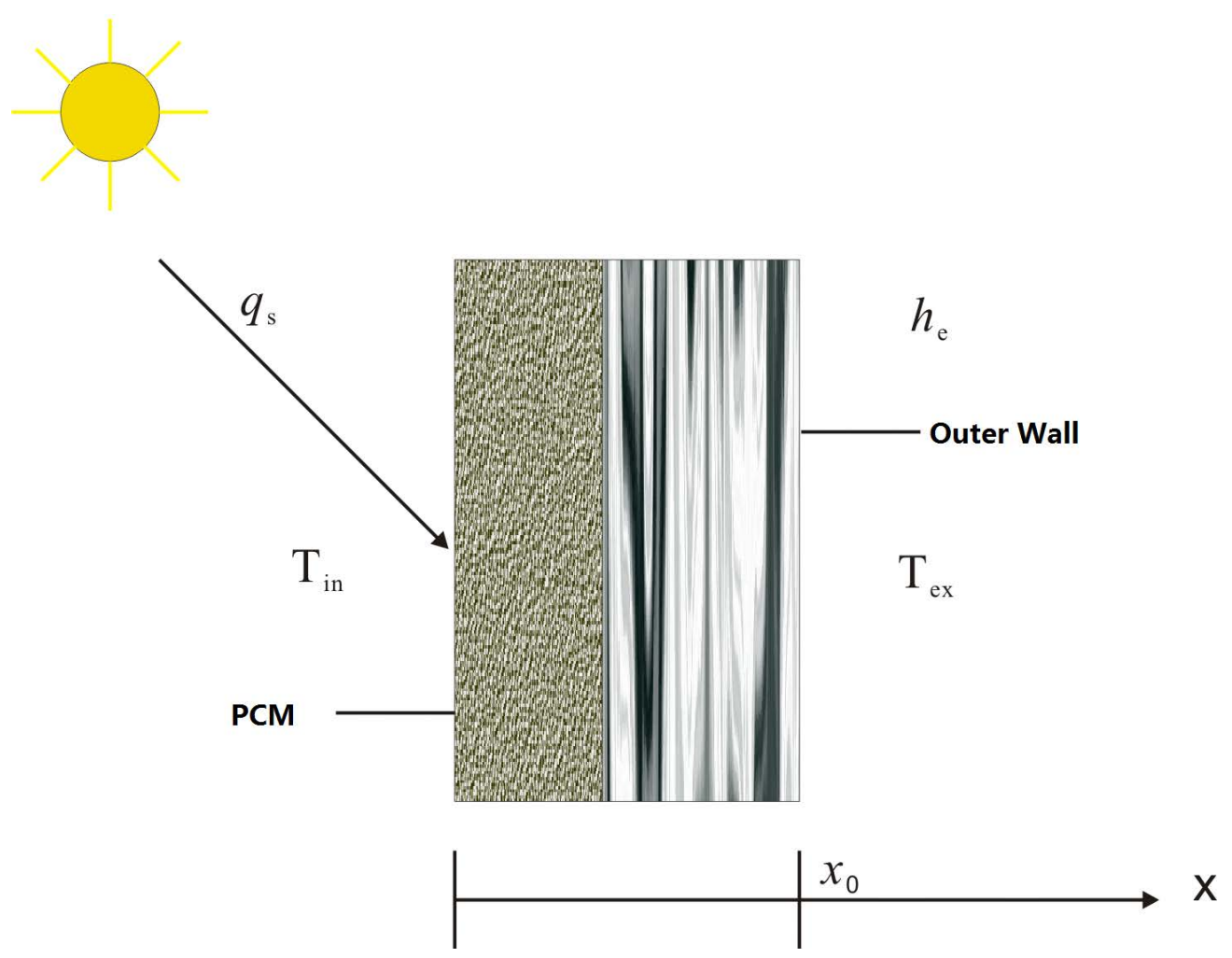

Figure 5. Thermal conduction model of wall. 


$$
\begin{gathered}
\rho \cdot \mathrm{C}_{p} \frac{\partial T(x, t)}{\partial t}=\lambda \cdot \frac{\partial^{2} s_{i}(x, t)}{\partial^{2} x^{2}}+S_{i} \\
-\lambda \frac{\partial T(x, t)}{\partial t}=h_{i}(t)\left(T_{i}-T(0, t)\right)+q_{a}(t) \\
-\lambda \frac{\partial T(x, t)}{\partial t}=h_{e}\left(T(0, t)-T_{e}\right)
\end{gathered}
$$

With:

- $C_{p}$ designs the specific heat capacity $\left(\mathrm{J} / \mathrm{kg} \cdot{ }^{\circ} \mathrm{C}\right)$,

- $h_{i}(t)$ is the internal convective heat exchange coefficient. $\left(\mathrm{W} / \mathrm{m}^{2} \cdot{ }^{\circ} \mathrm{C}\right)$,

- $h_{e}$ represents the external convective heat exchange coefficient. $\left(\mathrm{W} / \mathrm{m}^{2} \cdot{ }^{\circ} \mathrm{C}\right)$,

- $S_{i}$ designs the equivalent flux from internal source due to latent heat $\left(\mathrm{W} / \mathrm{m}^{2}\right)$,

- $q_{a}(t)$ is the density of flux absorbed $\left(\mathrm{W} / \mathrm{m}^{2}\right)$,

- $T(x, t)$ represents the variation function of the temperature $\left({ }^{\circ} \mathrm{C}\right)$,

- $T_{i}\left({ }^{\circ} \mathrm{C}\right)$ is the internal temperature $\left({ }^{\circ} \mathrm{C}\right)$,

- $\mathrm{T}_{e}\left({ }^{\circ} \mathrm{C}\right)$ is the external temperature $\left({ }^{\circ} \mathrm{C}\right)$,

- $x$ designs the distance $(\mathrm{m})$,

- $t$ represents the time (s).

The values of the latent or fusion heat $\Delta h_{f}$, and the solidification rate, $\frac{\mathrm{d} f_{s}}{d t}$ can be obtained by applying the Differential Scanning Calorimeter (DSC), where $f_{s}$ represents the solid fraction. Then, the system can be easily solved using the explicit finite difference method which allows the use of nonlinear transfer coefficient and time-dependent heat sources. Figure 6 illustrates the simulation results of the behavior for different types of walls (Plaster Boars or "PB", Phase Change Material or "PCM" and Regular Concrete or "RC" in a day. Thus, from the obtained results and for thermal energy storage techniques, the PCM are presented as the best choice to be implemented in the wall due to their lower discharging time in cooling and in heating conditions to noticeably improve indoor temperature. PCM limits the temperature varied range into $1^{\circ} \mathrm{C}$, which have an advantage over regular concrete, because RC can limit to $4^{\circ} \mathrm{C}$. The result shows bright future of new energy application in building.

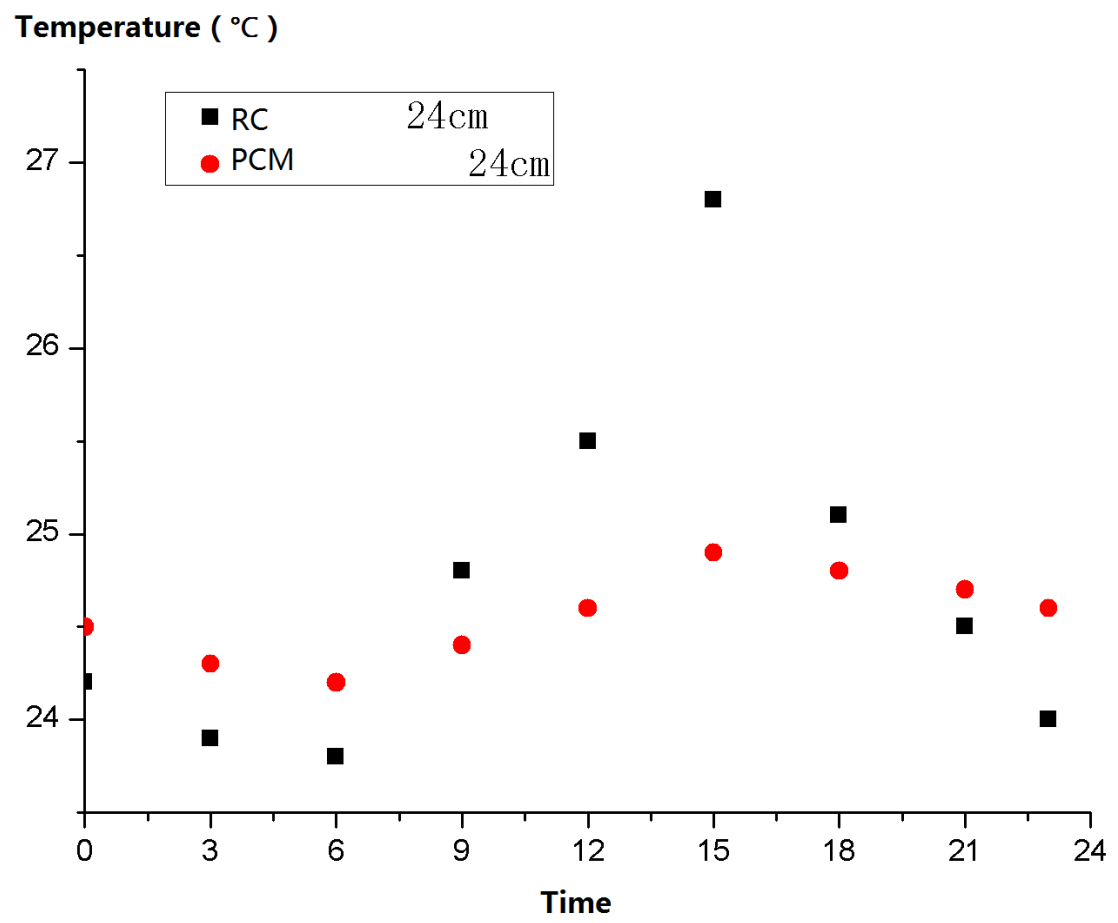

Figure 6. PCM's influence on indoor temperature. 


\section{Conclusion}

Effect of PCM on indoor temperature control is analyzed by the terms of building simple mathematic model. It comes to a conclusion that construction energy waste can be cut down by reasonable design and adopting suitable material. The model can be used to analyze more complex structure and it establishes a basis to design and analyze house wall implemented PCM.

\section{References}

[1] Renewable Energy 21 (REN21), Renewable Energy Report in 2015.

[2] UK Department of Energy and Climate Change, Energy Consumption in the UK (2015), 30 July 2015.

[3] Neeper, D.A. (2000) Thermal dynamic of Wallboard with Latent Heat Storage. Solar Energy, 68, 393-403. http://dx.doi.org/10.1016/S0038-092X(00)00012-8

[4] Hawes, D.H. and Feldman, D. (1992) Absorption of Phase Change Materials in Concrete. Solar Energy Materials and Solar Cells, 27, 91-101. http://dx.doi.org/10.1016/0927-0248(92)90112-3

[5] Whiffen, T.R. and Riffat, S.B. (2013) A Review of PCM Technology for Thermal Energy Storage in the Built Environment: Part II. International Journal of Low-Carbon Technologies, 8, 59-164.

[6] Peippo, K., Kauranen, P. and Lund, P.D. (1991) A Multicomponent PCM Wall Optimized for Solar Heating. Energy and Buildings, 17, 259-270. http://dx.doi.org/10.1016/0378-7788(91)90009-r

[7] Fourier Series Solution of the Heat Equation. www.math.vt.edu/people/dlk/m2k_opm_fsolht.pdf

\section{Submit or recommend next manuscript to SCIRP and we will provide best service for you:}

Accepting pre-submission inquiries through Email, Facebook, LinkedIn, Twitter, etc.

A wide selection of journals (inclusive of 9 subjects, more than 200 journals)

Providing 24-hour high-quality service

User-friendly online submission system

Fair and swift peer-review system

Efficient typesetting and proofreading procedure

Display of the result of downloads and visits, as well as the number of cited articles

Maximum dissemination of your research work

Submit your manuscript at: http://papersubmission.scirp.org/ 